\title{
EL PÚlPito DEL TEMPLO DE MOTUL
}

\section{Por Elisa Vargas Lugo}

En el convento franciscano de la ciudad de Motul en la península yucateca se encuentra un púlpito de madera tallada de gran interés artístico por su carácter formal, derivado de las corrientes artísticas del xVI.

Según el padre López de Cogolludo este convento fue fundado en 15671 pero no fue sino hasta la centuria siguiente cuando la construcción del convento se llevó al cabo. El mismo López de Cogolludo nos dice que el padre fray Diego de Cervantes, guardián del convento en 1648:

... subió las murallas de la iglesia, cubrió la capilla mayor de media naranja y el cuerpo de la iglesia de cañón de bóveda, aunque faltando no más que lo que coge el coro, por cubrir, enfermó y murió de peste en 1648. .... EI trazo de la iglesia de Motul lo hizo el P. Fr. Marcos de Manzista que sin ser arquitecto, era muy capaz. Esta iglesia la acabó el P. Fray José de Narváez, siendo guardián del convento. 2

Estas informaciones coinciden perfectamente con la fecha de terminación del templo, que se encuentra inscrita en la fachada y que es la de 1651. Por lo tanto la obra que nos ocupa debió ser hecha en el siglo Xvir -aunque formalmente se relacione más con las obras del xvi, que con las del xvir ya barrocas-, pues antes, no estando construida la iglesia, no es posible que se pensara en la existencia del púlpito.

Éste está estructurado por medio de doce caras, seis más anchas que las otras seis. En las caras más anchas aparecen figuras de santos frailes entre las que se distinguen la de Santo Tomás de Aquino y la de San Francisco. Entre cada santo se encuentra una figura de cariátide colocada en planos que sobresalen sobre los paños en que están las figuras de los frailes, queclando éstos encerrados en una especie de nichos poco profundos, según puede apreciarse en las fotografías que ilustran este artículo. Todas las figuras de los santos varones levantan sus cabezas hacia la parte superior del púlpito indicando asf la atención con que deben escucharse las santas palabras del predicador (láminas 2 y 3).

1 Cogolludo Fray Diego López. Historia de Yucatán, México. Editorial Academia Literaria, 1957. Lib. 48 Cap. xx p. 297.

2 Catálogo de construcciones religiosas del Estado de Yucatán. Recopilación de Justino Fernández. México. Secretaría de Hacienda y Crédito Público. Talleres Gráficos de la Nación. 1945, t. Ir, p. 499. 
Esta obra, de talla como hemos dicho, estuvo estofada y todavia pueden verse restos del oro laminado que antes la revestia, debajo de la capa de pintura que la cubre. Artísticamente la pieza se presenta, a los ojos del espectador dentro de un contra punto formal muy sutil. Se destacan, igualmente potentes, unos valores arcaizantes intimamente unidos a otros de linaje renacentista. Los relieves planos que aparecen en muchas partes de las figuras, así como la ingenuidad con que está resuelta su anatomia, recuerdan ciertas obras romanizantes al mismo tiempo que de ellos se desprende una finura y delicadeza de expresión que rebasando este gusto parece perseguir una meta formal más naturalista, más culta. Asf, aunque la mayor parte de la talla presenta soluciones ingenuas y desproporcionadas - por ejemplo el tratamiento de los paños sobre todo en las figuras de las cariátides o el aplanamiento de los volúmenes en general-, las figuras de monjes y de cariátides tienen una indefinible elegancia y la dulzura de sus rostros y actitudes suaviza el oficio de cepa popular. En suma se trata de una preciosa obra representativa de las primicias hibridas del arte mexicano, propias del fenómeno de aculturación al arte occidental. Finalmente hemos de advertir que esta obra recuerda los magníficos altares del templo de Mani, en el mismo Estado, en los cuales las características de la talla son muy parecidas a las mencionadas aquí y en donde se emplearon también cariátides en la composición, si bien esas obras en su conjunto parecen de oficio más culto, que el púlpito que presentamos aquí. 


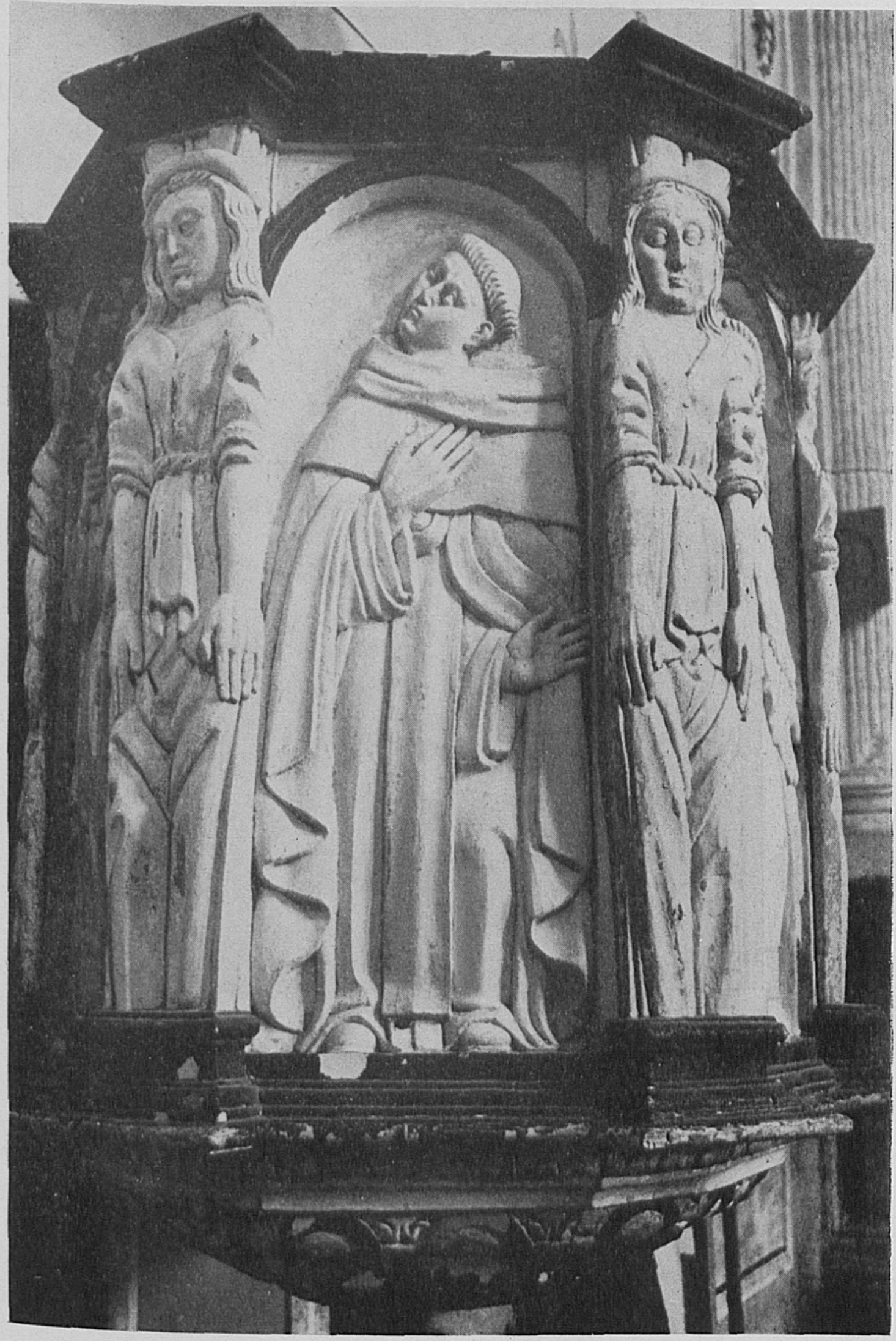


DOI: http://dx.doi.org/10.22201/iie.18703062e.1968.37.863

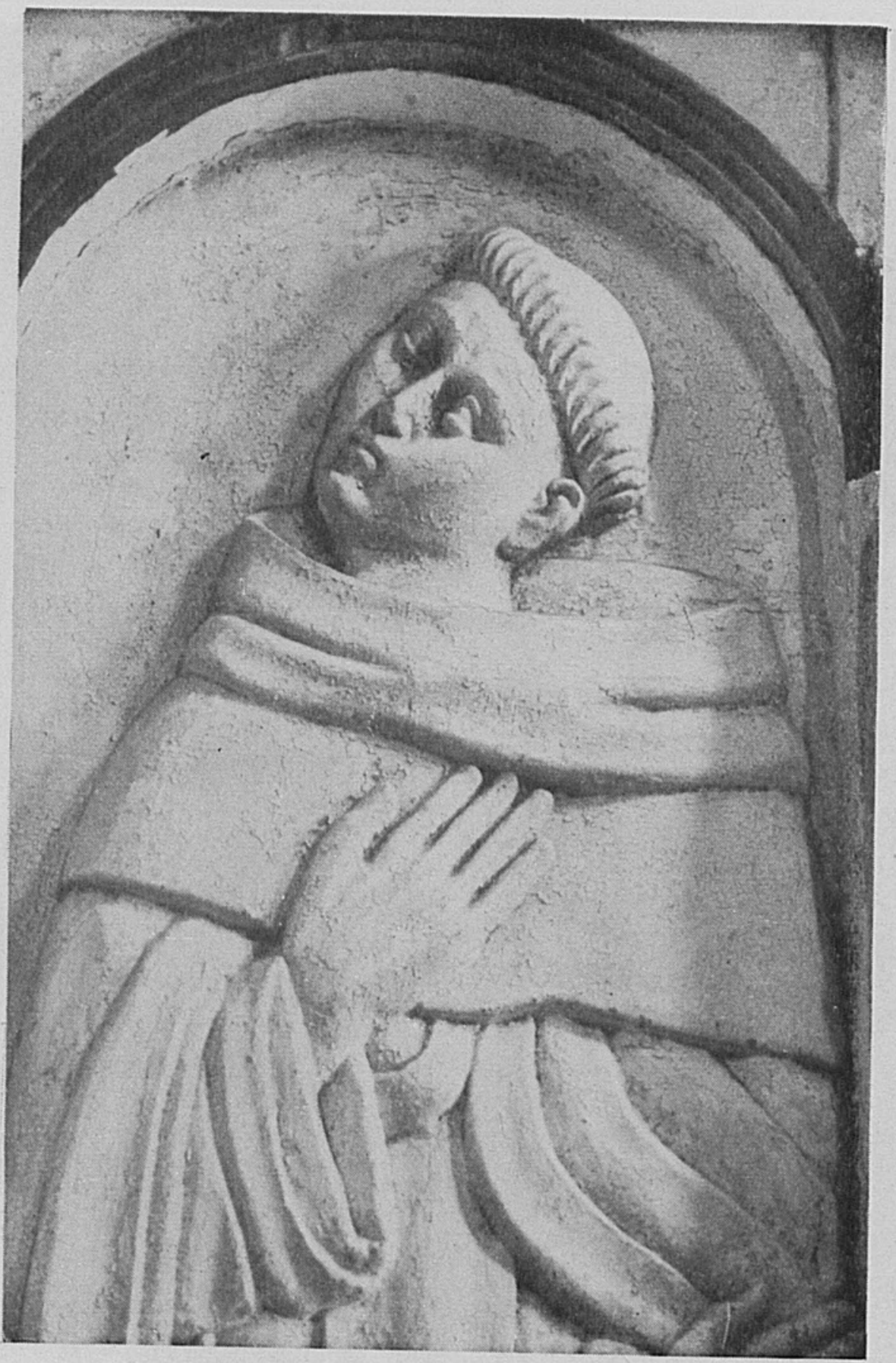

2. Motul, Yuc. Púlpito. Detalle 
DOI: http://dx.doi.org/10.22201/iie.18703062e.1968.37.863

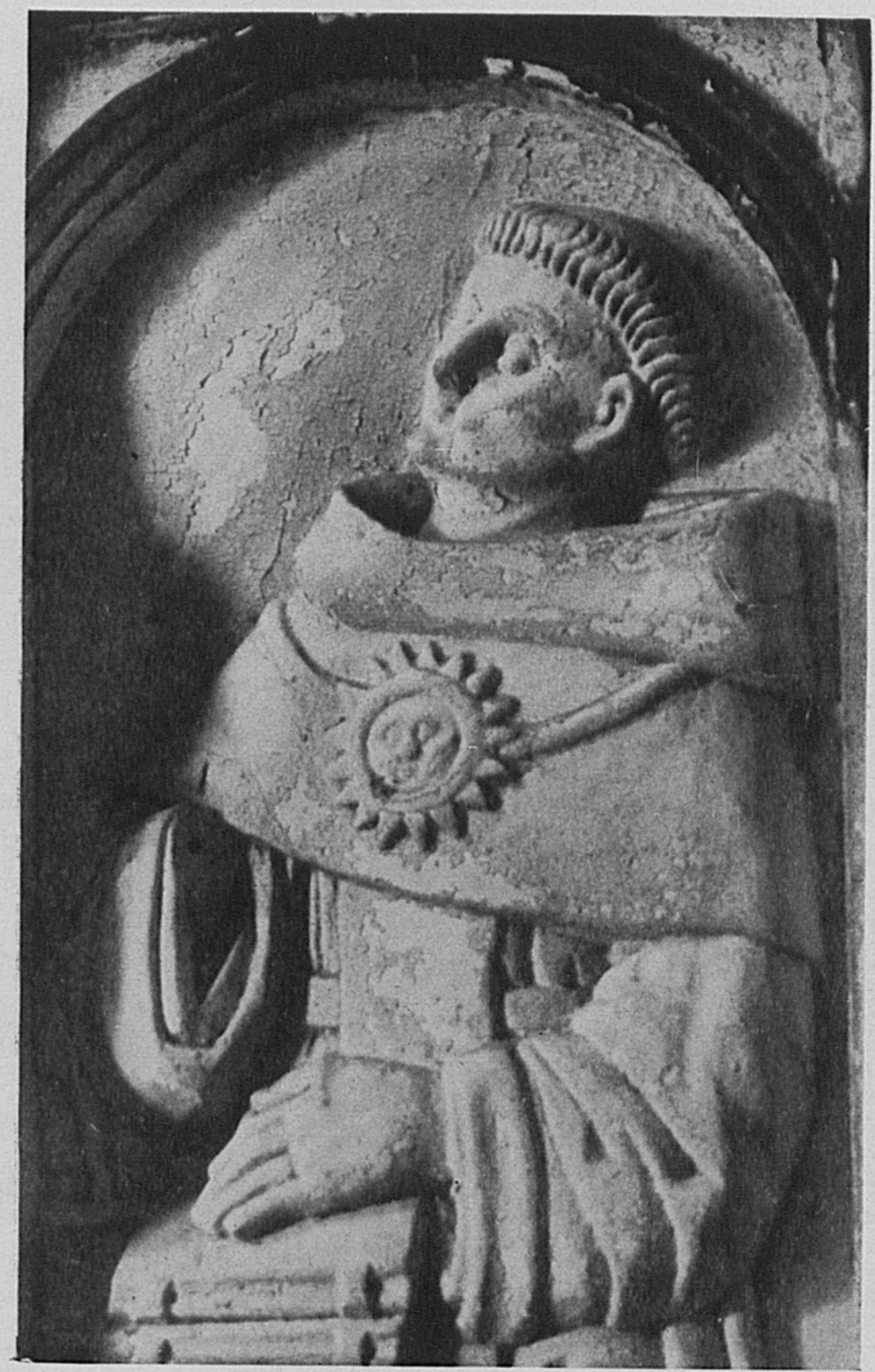

3. Motul, Yuc. Púlpito. Santo Tomás de Aquino. El sol alude a su sabiduría y la cadena que lo sostiene a su obra Catena aurea 


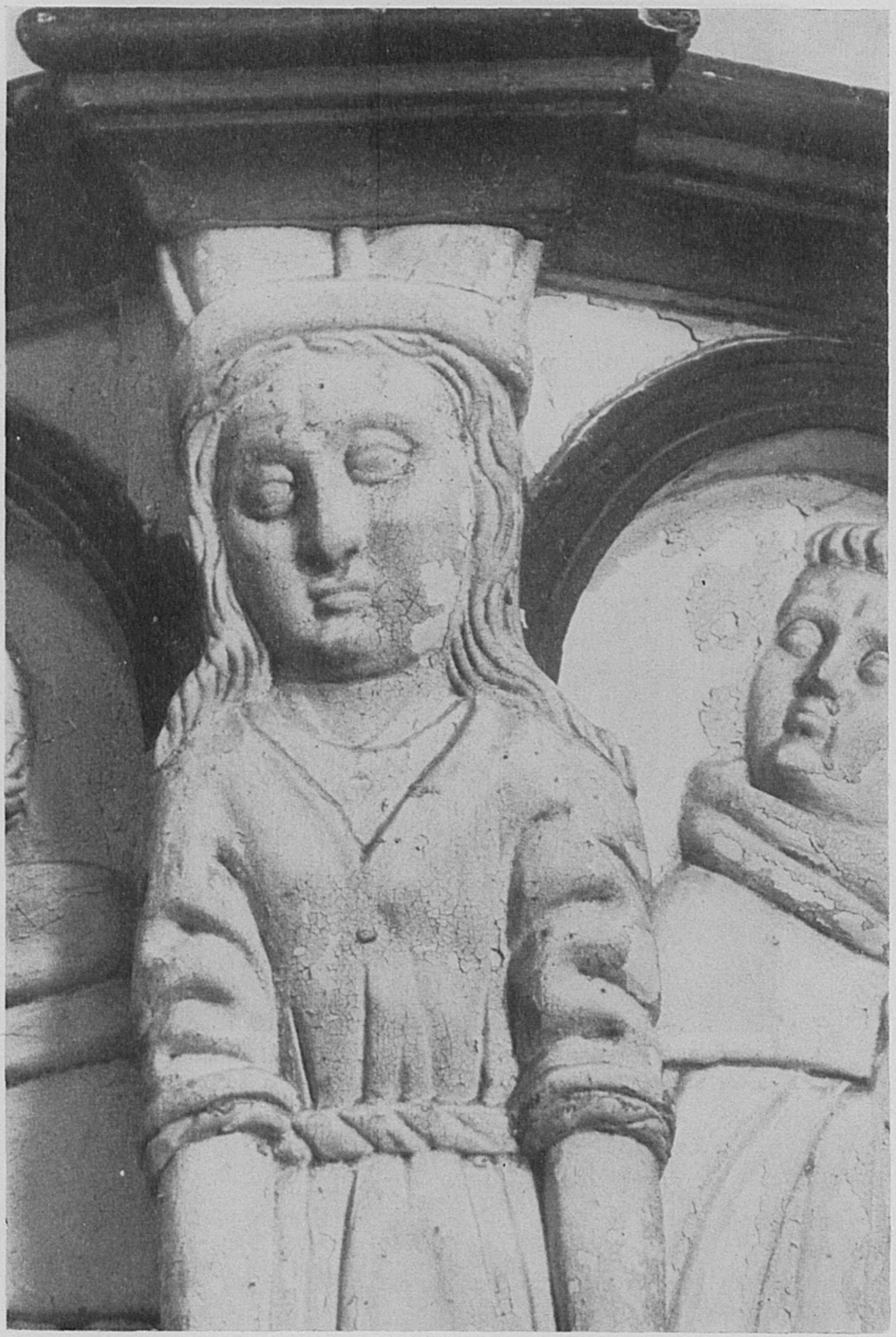

4. Motul, Yuc. Púlpito. Detalle 